\title{
Influence of Macrocycle Protonation on the Photophysical Properties of Porphyrins
}

\author{
Mikalai M. Kruk, ${ }^{a} @$ Alexander S. Starukhin, ${ }^{a}$ and Wouter Maes ${ }^{\mathrm{b}, \mathrm{c}}$ \\ ${ }^{a}$ B.I. Stepanov Institute of Physics of National Academy of Sciences, 220072 Minsk, Republic of Belarus \\ ${ }^{\mathrm{b}}$ Institute for Materials Research (IMO), Research Group Organic and (Bio)Polymer Chemistry, Hasselt University, B-3590 \\ Diepenbeek, Belgium \\ 'Molecular Design and Synthesis, Department of Chemistry, Katholieke Universiteit Leuven, B-3001 Leuven, Belgium \\ @Corresponding authorE-mail: kruk@imaph.bas-net.by
}

\begin{abstract}
Analysis of the relationship between the molecular structure of porphyrins and the spectral features of their monoand diprotonated forms in solution is presented. The evolution of the concept of the role of acid-base equilibria in the formation of the spectral properties and the excitation energy deactivation pathways in porphyrins are reviewed. The trends observed in the fluorescence and intersystem crossing quantum yields on going from free base porphyrins to their mono- and diprotonated forms are analyzed, and the mechanisms involved are discussed.
\end{abstract}

Keywords: Porphyrin, monoprotonated form, excited states, intersystem crossing, internal conversion, fluorescence, heavy atom effect.

Porphyrins are known to be amphoteric compounds having properties of both acids and bases in solution. ${ }^{[1]}$ Their basic properties result in protonation of the pyrrolenic nitrogen atoms in an acidic environment with formation of mono- and diprotonated species (denoted in Scheme 1 as MP and DP, respectively). The basic properties of porphyrins have received much more attention as compared with their acidic features and numerous papers have been published on this issue during the period from the middle of the last century to the date. ${ }^{[1-5}$ and refs therein]

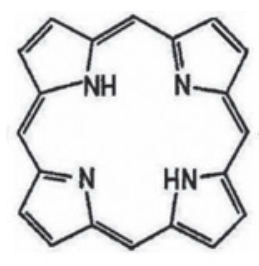

FB

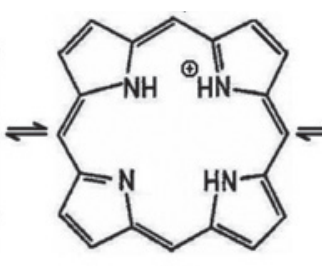

MP

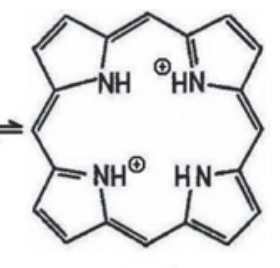

DP
Scheme 1.

Renewed interest to the protonated forms of porphyrins has arisen in the early nineties and lasts up until now since the diprotonated species are considered as useful model compounds to study the features of nonplanar distortion of tetrapyrrolic macrocycles and their molecular flexibility. ${ }^{[6-9]}$ In this framework, essential progress has been achieved in the elucidation of the molecular conformation of diprotonated forms, ${ }^{[4-15]}$ and the type and extent of macrocycle nonplanar distortions have been extensively discussed in terms of molecular flexibility, ${ }^{[7,9,15]}$ the peripheral substitution pattern, ${ }^{[6,7,9,14,15]}$ and the strength of intermolecular interactions with acid residues and other anionic species in solution. [14,16,17] The relationship between the molecular structure and macrocycle core acid-base equilibrium has been studied. ${ }^{[16,18-}$ 22] Studies of the excited states properties of diprotonated porphyrins have revealed dramatic changes in the rates and channels of the excitation energy deactivation as compared with those for the free bases, and different mechanisms involved in these changes have been proposed. ${ }^{[6,15,16,23-26]}$

Much less is known about the molecular conformation and optical properties of monoprotonated forms of porphyrins. ${ }^{[16,21,26-29]}$ Mainly, this is because, in contrast with diprotonated species, it is not so easy to observe monoprotonated porphyrins in solution. Starting from the early titration studies, ${ }^{[30]}$ the free base and diprotonated molecules have been observed only in most cases. Lacking of isobestic points in the absorption titration experiments has been pointed out as evidence for formation of monoprotonated forms of the studied derivatives. ${ }^{[16,21]}$ Confident formation of monoprotonated forms of $\beta$-alkyl-substituted porphyrins was reported and their electronic and IR absorption spectra have been measured and analyzed, ${ }^{[27-29]}$ while the monoprotonated forms of meso-aryl-substituted derivatives have not been described for a long time. In several cases, ${ }^{[16-21]}$ the spectral features of the monoprotonated forms of mesoarylsubstituted compounds have been derived from global analysis of the electronic absorption and fluorescence spectra and time-resolved fluorescence measurements, taken during the titration experiments. Monoprotonated forms of mesoaryl-substituted porphyrins were also obtained by means of structural modification with hydrocarbon-capped moieties facing the macrocyclic plane, ${ }^{[31]}$ and by complexation of the diprotonated form with bulky and poorly coordinating anions followed by dilution to decrease the solution acidity. ${ }^{[26]}$

In this paper, we present a critical review of the optical spectral features and excited states properties of mono- and diprotonated porphyrins, based on the data published from the middle of the fifties of last century to date. A generalization of available experimental and theoretical data is proposed and the main features of the contemporary understanding of the problem under consideration are summarized. The review does not intend to compile all the published articles on this subject, but gathers the most important "cornerstone" studies to trace the evolution of knowledge and to give 
a feeling of the modern state of facts in the field. For this purpose, a special set of experiments has been carried out to present the spectral and photophysical features of the monoand diprotonated forms of porphyrins with the most common types of substitution.

\section{Molecular Symmetry and Electronic Absorption Spectra of Protonated Porphyrins}

Attachment of one or two protons to pyrrolenyne rings in the porphyrin macrocyclic core with formation of mono(MP) and diprotonated (DP) species leads to substantial conformational changes of the molecule. ${ }^{[4,7,26]}$ On going from free base molecules (FB) to monoprotonated species (MP), the molecular symmetry decreases. The point group symmetry $C_{2 \mathrm{v}}$ corresponds to the MP species, whereas FB molecules belong to the $D_{2 \mathrm{~h}}$ symmetry point group. ${ }^{[28]}$ Diprotonated (DP) species formally belong to the $D_{4 \mathrm{~h}}$ symmetry point group as it is the case for porphyrin metallocomplexes. ${ }^{[3,4]}$ Steric interaction of the additional proton attached to the pyrrolenyne ring for MP (or two attached pyrrolenyne protons in the case of DP) with pyrrole NH-protons prevents all them to lie in the same porphyrin macrocyclic plane. Thus, in DP species the mutual repulsion of four hydrogen atoms in the macrocyclic core leads to substantial tilting of the pyrrole rings (with the latter themselves being almost planar), in such a way that the pairs of two opposite nitrogen atoms are at opposite sides of the macrocycle mean plane. ${ }^{[4,7,19]}$ As a rule, these nonplanar conformers show a saddle-type distortion of the macrocycle. However, mixed saddle- and ruffletype distortion has been found in some cases as a result of coupling with steric hindrance due to peripheral substitution. [14] The tilting angle $\varphi$ depends on the type of macrocycle substitution and can vary from $9-14^{\circ}$ for DP of porphin and its $2,3,7,8,12,13,17,18$-octa- $\beta$-alkyl derivatives up to $30^{\circ}$ in the case of the DP form of 5,10,15,20-tetraphenylporphin. ${ }^{[4,7]}$ As a result, the molecular symmetry of these nonplanar saddle-type distorted DP species decreases to $D_{2 \mathrm{~d}}{ }^{[4,7,32]}$ Nevertheless, in solution, because of rapid exchange of the inner hydrogen atoms with solvent protons, the diprotonated porphyrin macrocycles can be considered as having a dynamically averaged $D_{4 \mathrm{~h}}$ symmetry, ${ }^{[33,34]}$ and a number of spectral features of DP species can be rationalized by this simplified approach.

It is known that the positively charged protonated macrocycle is able to form hydrogen bonds with negatively charged acid residues in solution. ${ }^{[1,4]}$ The strength of this hydrogen bond depends on multiple factors, the mostimportant being the Coulomb attraction, repulsive orbital interactions (Pauli repulsion) and bonding orbital interactions. ${ }^{[14]}$ In case of the DP form the anions were found to be on the molecular symmetry axis at both sides of the porphyrin macrocycle, ${ }^{[4,7]}$ so the molecular symmetry is retained upon complexation. ${ }^{[4]}$

The electronic absorption spectra of MP and DP forms were measured for a number of porphyrin derivatives..$^{[1,3,4,14,16-}$ 24,26-28,30,35-37] The spectral features of the MP and DP forms for a series of porphyrins with the most common substitution patterns are presented and discussed in details below. The series includes the free base porphin $\left(\mathrm{H}_{2} \mathrm{P}\right)$, asymmetrically substituted free base 2,7,12,17-tetramethylporphin ( $\left.\mathrm{H}_{2} \mathrm{TMP}\right)$, free base 2,3,7,8,12,13,17,18-octamethylporphin ( $\left.\mathrm{H}_{2} \mathrm{OMP}\right)$,
N-substituted free base 21-methyl-2,3,7,8,12,13,17,18octaethylporphin $\left(\mathrm{H}\left(\mathrm{N}-\mathrm{CH}_{3}\right) \mathrm{OEP}\right)$, free base 5,10,15,20tetraphenylporphin ( $\left.\mathrm{H}_{2} \mathrm{TPP}\right)$ and free base 5,10,15,20tetramesitylporphin ( $\mathrm{H}_{2}$ TMesP).

The FB porphin absorption spectrum consists of four distinct bands in the visible range with maxima at 615, 562, 518 and $488 \mathrm{~nm}$ in THF (Figure 1a). Pronounced changes in the absorption spectrum are observed upon the formation of the MP species. According to the proposed interpretation, ${ }^{[28]}$ the main reason for the observed spectral changes is the substantial decrease of the $\Delta E\left(\mathrm{~S}_{2}-\mathrm{S}_{1}\right)$ splitting value upon attachment of the proton. The value of the $\Delta E\left(\mathrm{~S}_{2}-\mathrm{S}_{1}\right)$ splitting between the two lowest singlet electronic states for the FB porphyrins amounts around $3000 \mathrm{~cm}^{-1}$, with in the particular case of $\mathrm{FB} \mathrm{H}_{2} \mathrm{P}$ being $\sim 3040 \mathrm{~cm}^{-1}$. Formation of the porphin MP species leads to a decrease in the $\Delta E\left(\mathrm{~S}_{2}-\mathrm{S}_{1}\right)$ splitting value down to $820 \mathrm{~cm}^{-1}$. As a result, the vibronic satellite of the first electronic transition $Q_{x}(0,1)$ overlaps with the second electronic transition band $Q_{\mathrm{y}}(0,0)$, giving rise to a three bands shape of the absorption in the visible range. For MP $\mathrm{H}_{2} \mathrm{P}$ two strong bands dominate in the spectrum (520 and $545 \mathrm{~nm}$ in THF) since the $Q_{\mathrm{x}}(0,0)$ band belonging to the first electronic transition has a much lower extinction coefficient (a very weak maximum is observed at $592 \mathrm{~nm}$ in THF). According to the Gouterman four-orbital model the two highest occupied molecular orbitals (HOMO) in the MP form, as it occurs also in the $\mathrm{FB}$ of $\mathrm{H}_{2} \mathrm{P}$, are quasidegenerate, giving rise to pronounced configuration interaction which leads to a decrease in the absorptivity of this transition. ${ }^{[38-39]}$ Formation of the DP species leads to a simplification of the spectral shape due to the molecular symmetry increase. The vibronic band peaking at $540 \mathrm{~nm}$ dominates in the spectrum measured in THF (Figure 1a). The 0-0 transition band is also very weak and appears as a shoulder at $\sim 585 \mathrm{~cm}^{-1}$. Thus, on going from FB to MP and then from MP to DP form, the long wavelength $Q$-band (0-0 transition) undergoes a progressive hypsochromic shift: $615 \mathrm{~nm} \rightarrow 592 \mathrm{~nm} \rightarrow 585 \mathrm{~nm}$. The Soret band has also distinctly different positions for the MP and DP forms as compared to that of the FB. Upon formation of the MP species an hypsochromic shift from 389 to $386 \mathrm{~nm}$ was measured, whereas attachment of the second proton led to a spectrum having the Soret band batochromically shifted to $393 \mathrm{~nm}$. Thus, the maximum of the Soret band for MP and DP species, being measured relatively to the position of the FB Soret band has shifts in the opposite directions.

The spectra of all the three forms for the $\beta$-alkylated porphyrin derivatives $\mathrm{H}_{2}$ TMP and $\mathrm{H}_{2} \mathrm{OMP}$ show the same behavior as described in detail above for the corresponding forms of $\mathrm{H}_{2} \mathrm{P}$ (Figure $1 \mathrm{~b}, \mathrm{c}$ ). However, some characteristic features observed for these derivatives should be pointed out. First of all, in these derivatives the long wavelength Q-band (0-0 transition) has a noticeably higher absorptivity giving rise to a distinct band in the spectra. Thus, the corresponding maxima in the spectra of MP and DP forms of $\mathrm{H}_{2} \mathrm{OMP}$ are at 600 and $589 \mathrm{~nm}$. The $\Delta E\left(\mathrm{~S}_{2}-\mathrm{S}_{1}\right)$ splitting value for the MP species is $989 \mathrm{~cm}^{-1}$ in this case. Therefore, overlapping of the vibronic satellite of the first electronic transition $Q_{\mathrm{x}}(0,1)$ and the second electronic transition $Q_{y}(0,0)$ bands is smaller. The sign of the band belonging to the second electronic transition $Q_{y}(0,0)$ of MP is clearly visible as a shoulder at $\sim 570 \mathrm{~nm}$. In case of the MP form of $\mathrm{H}_{2} \mathrm{TMP}$ the $\Delta E\left(\mathrm{~S}_{2}-\mathrm{S}_{1}\right)$ splitting 

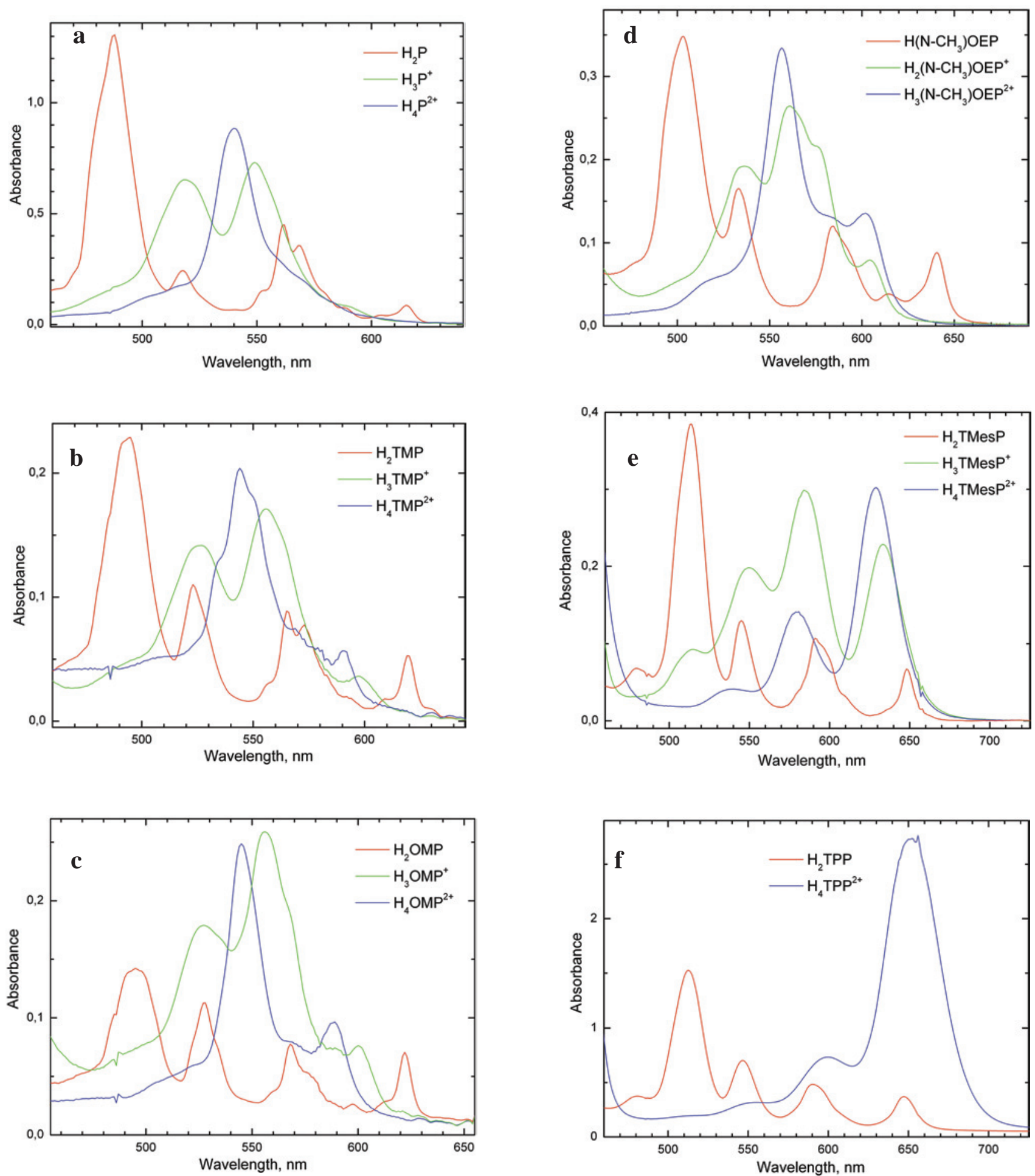

Figure 1. Ground state absorption spectra of the FB, MP and DP forms of porphyrins in equimolar concentrations: a) $\mathrm{H}_{2} \mathrm{P}$; b) $\mathrm{H}_{2}$ TMP; c) $\mathrm{H}_{2} \mathrm{OMP}$; d) $\mathrm{H}\left(\mathrm{N}-\mathrm{CH}_{3}\right) \mathrm{OEP}$; e) $\mathrm{H}_{2}$ TMesP; f) $\mathrm{H}_{2}$ TPP.

value of $1025 \mathrm{~cm}^{-1}$ is close to that measured for $\mathrm{MP} \mathrm{H}_{2} \mathrm{OMP}$ and the distinct shoulder belonging to the $Q_{\mathrm{y}}(0,0)$ band is observed too.

Formation of the DP form of $\mathrm{H}_{2}$ TMP and $\mathrm{H}_{2} \mathrm{OMP}$ leads to a spectrum similar to that for the DP form of $\mathrm{H}_{2} \mathrm{P}$. At the same time, keeping the same trend, the DP spectrum for the former has its own specific features. These features arise from the lower molecular symmetry due to asymmetry in the peripheral substitution. It is known that isolated molecules of porphyrin metallocomplexes have symmetry point group $D_{4 \mathrm{~h}}$ and their singlet and triplet states are twofold degenerate. ${ }^{[40]}$ This degeneration is lifted for the molecules in fluid solution and especially in rigid environment. ${ }^{[41]}$ For metallocomplexes of symmetrically substituted porphyrin derivatives as well as for metallocomplexes of unsubstituted porphin the splitting value exceeds a few tens of wavenumbers. ${ }^{[41-46]}$ As it was found in case of the $\mathrm{H}_{2}$ TMP complex with $\mathrm{Zn}^{\mathrm{II}}$ and $\mathrm{Pd}^{\mathrm{II}}$ ions, lifting in the degeneracy of two lowest singlet electronic 
states occurred. ${ }^{[42,43]}$ The amount of the $\Delta E\left(\mathrm{~S}_{2}-\mathrm{S}_{1}\right)$ splitting due to this asymmetrical substitution was found to be as high as 260 and $215 \mathrm{~cm}^{-1}$ for the former and latter cases, respectively, being almost one order of magnitude larger than in the case of symmetrically substituted derivatives. Therefore, two separate distinct bands belonging to the $S_{1}$ and $\mathrm{S}_{2}$ states can easily be observed in the absorption and fluorescence spectra of metallocomplexes of asymmetrically substituted porphyrin macrocycles. High molecular symmetry in case of DP species (formally $D_{4 \mathrm{~h}}$, as it was stated above) leads to relatively small $\Delta E\left(\mathrm{~S}_{2}-\mathrm{S}_{1}\right)$ splitting, of the same order of magnitude as for metallocomplexes. ${ }^{[23]}$ Therefore, asymmetrical substitution is able to create much higher perturbation and can affect the degeneration of the singlet states in a stronger way as compared to that originating from environmental effects. As a result, the bands at 591 and $581 \mathrm{~nm}$ in the absorption spectrum of DP $\mathrm{H}_{2}$ TMP are due to $\mathrm{S}_{0} \rightarrow \mathrm{S}_{1}$ and $\mathrm{S}_{0} \rightarrow \mathrm{S}_{2}$ transitions, respectively. At the same time, it should be stressed that there are no peculiarities in the formation of the protonated forms. Thus, both porphyrins with symmetrical and asymmetrical substitution pattern form mono- and diprotonated species and have spectral features close to each other.

The pyrrole proton in the macrocycle core can be substituted with either alkyl or aryl groups. ${ }^{[35,47-49]}$ This substitution strongly affects the geometry of the porphyrin macrocycle since the core cavity is too small to accommodate these bulky substituents. ${ }^{[4,49-50]}$ It was expected that even in the case of pyrrole nitrogen methylation substantial nonplanar distortions take place. ${ }^{[50]}$ The question then arose if this class of porphyrins showed any features for the protonated forms different from those found for the porphyrins substituted on the periphery. ${ }^{[35,37]}$ The absorption spectra for the FB, $\mathrm{MP}$ and DP forms of $\mathrm{H}\left(\mathrm{N}-\mathrm{CH}_{3}\right) \mathrm{OEP}$ are shown in Figure 1d. The absorption spectra show similarity to those for $\mathrm{H}_{2} \mathrm{OMP}$, but some differing points can be discussed. The $\mathrm{N}-\mathrm{CH}_{3}$ substitution leads to a bathochromic shift for the $0-0$ transition band, amounting to $460 \mathrm{~cm}^{-1}$, as compared to that for $\mathrm{H}_{2} \mathrm{OMP}$ (Figure 1c) or $\mathrm{H}_{2} \mathrm{OEP}{ }^{[35]}$ The $\Delta E\left(\mathrm{~S}_{2}-\mathrm{S}_{1}\right)$ splitting value for the MP molecules is $822 \mathrm{~cm}^{-1}$, being very close to that measured for the MP species of $\mathrm{H}_{2} \mathrm{P}$, but about $150 \mathrm{~cm}^{-1}$ less than for the MP form of $\mathrm{H}_{2} \mathrm{OMP}$. An important point is that the hypsochromic shifts upon formation of the protonated species for $\mathrm{H}\left(\mathrm{N}-\mathrm{CH}_{3}\right) \mathrm{OEP}$ are also higher. Taking into account that the $\mathrm{CH}_{3}$ group is a weak electron donor, one can expect that the main reason of the large spectral differences in case of the FB species arise from the structural differences due to out-of-plane tilting of the $N$-alkylated pyrrole ring. The MP and DP species of both molecules seem to have very similar (especially in the case of the MP species) distorted geometries, so the structural differences upon formation of the protonated species would be negligible. As a result, the energy of the $0-0$ transitions will be about the same in these cases.

The main difference in the structures of the two mesotetraarylsubstituted porphyrins is the possibility for the aryl rings to rotate in $\mathrm{H}_{2} \mathrm{TPP}$ and the steric hindrance for aryl ring rotation (due to two ortho-substituted $\mathrm{CH}_{3}$ groups) in $\mathrm{H}_{2}$ TMesP. These structural differences are of utmost importance for the protonation processes. ${ }^{[7,15]}$ Thus, analysis of the spectra presented in Figure if clearly demonstrates the uniqueness of $\mathrm{H}_{2}$ TPP as concerns the formation of the MP species. Under the given experimental conditions there are no noticeable deviations from the isobestic points at 470 and $559 \mathrm{~nm}$ for the FB/DP equilibrium, thus indicating the intermediate MP species formation. The same set of isobestic points holds during the whole titration. This means that the protonation constants for the formation of both MP and DP species should be very close, i.e. $\mathrm{p} K_{\mathrm{a}}{ }^{4} \approx \mathrm{p} K_{\mathrm{a}}{ }^{3}$. Recent measurements for a series of para-phenyl-substituted $\mathrm{H}_{2}$ TPP derivatives have demonstrated two barely distinguishable steps in the protonation curve referring to $\mathrm{FB} / \mathrm{MP}$ and $\mathrm{MP} /$ DP equilibria, with two $\mathrm{p} K$,'s close to each other, resulting in spectra of FB and DP forms being observed only in the course of the titration, without any features of MP species. ${ }^{[22]}$ These findings are in line with numerous published reports on the protonation of $\mathrm{H}_{2} \mathrm{TPP}$, where a single FB/DP species equilibrium has been observed in both absorbance and fluorescence titration experiments. ${ }^{[4,21,37]}$ The maximum of the 0-0-transition for the DP form of $\mathrm{H}_{2}$ TPP lies at 652 $\mathrm{nm}$, shifted bathochromically relative to the free base form. ${ }^{[4]}$ This is in contrast with all the cases discussed above where the absorption spectra in the visible range for both MP and DP species have been hypsochromically shifted relative to those that measured for the corresponding FB forms. The bathochromic shift measured for the DP form of $\mathrm{H}_{2} \mathrm{TPP}$ was proposed to be due to phenyl ring rotation toward a more coplanar geometry, i.e. a conformation with a smaller dihedral angle $\theta$ between the porphyrin mean plane and that of the aryl rings, ${ }^{[7,24]}$ since this geometry is known to result in a batochromically shifted absorption spectrum. ${ }^{[1,51]}$

In the case of $\mathrm{H}_{2}$ TMesP the spectral features indicate that the protonation occurs with sequential formation of the MP and DP forms (Figure 1e), i.e. in a manner similar to that found for $\mathrm{H}_{2} \mathrm{P}$ and its alkylated derivatives (Figures 1a-d). The maxima of the 0-0 transitions for the MP and DP forms of $\mathrm{H}_{2}$ TMesP lie at 634 and $629 \mathrm{~nm}$, respectively, thus showing an hypsochromic shift relative to the maximum of the 0-0 transition of the FB form. However, the values of the hypsochromic shift are substantially lower in this case as compared to those in the case of $\mathrm{H}_{2} \mathrm{OMP}$. Shifts around 360 and $590 \mathrm{~cm}^{-1}$, versus 490 and $900 \mathrm{~cm}^{-1}$, have been measured for the MP and DP forms of $\mathrm{H}_{2}$ TMesP and $\mathrm{H}_{2} \mathrm{OMP}$, respectively. Thus, ortho-substitution of the phenyl rings with groups that prevent the meso-phenyl rings to rotate freely leads to an hypsochromic shift of the absorption spectrum of the DP form of $\mathrm{H}_{2}$ TMesP as compared to that for the DP species of $\mathrm{H}_{2}$ TPP: ${ }^{[17,18]} 414$ $\mathrm{cm}^{-1}$ (2-methylphenyl), $561 \mathrm{~cm}^{-1}$ (2,6-dimethylphenyl) and $566 \mathrm{~cm}^{-1}$ (2,6-difluorophenyl). One should note that the main difference in this shift values is due to the number of appended substituents, i.e. between 2- and 2,6-substituted derivatives, whereas the nature of the substituent plays a minor role (provided that their bulkiness is of the same order of magnitude). Since the position of the maxima in the absorption spectrum is proportional to the dihedral angle $\theta$ between the porphyrin mean plane and that of the aryl ring, ${ }^{[11,51]}$ this feature should be considered as an evidence for a geometry with a substantially higher $\theta$ value in the case of the DP form of $\mathrm{H}_{2}$ TMesP. These spectral data parallel with X-ray data, ${ }^{[7]}$ where it was found that the dihedral angle $\theta$ value is more than $30^{\circ}$ higher, i.e. being 
more "orthogonal", in the case of the DP form of $\mathrm{H}_{2}$ TMesP as compared to that for the DP form of the $\mathrm{H}_{2}$ TPP.

The whole set of X-ray data, results of quantum-chemical calculations, and measurements of spectral-luminescent and photophysical properties of meso-aryl-substituted porphyrins indicate that the extent of the saddle-type macrocycle distortion on the one hand, and the degree of coplanarity of the macrocycle and aryl substituents on the other hand, are interrelated parameters. This interrelationship has been studied recently. ${ }^{[15]}$ It was shown that saddle-type macrocycle distortion and a decrease in the value of the dihedral angle $\theta$ are correlated with electronic factors. Saddle-type distortion allows overcoming the steric hindrance and favors the coplanar conformation of the macrocycle and meso-arylsubstituents, which is energetically favorable. At the same time the need of the energy for the formation of the saddletype conformation counteracts this structural rearrangement. The equilibrium conformation of the molecule results from the influence of peripheral substitution and external forces due to the microenvironment. In order to relieve the steric repulsion of the inner hydrogen atoms in the macrocyclic core of the DP form, a pyrrole tilting angle (saddling angle) $\varphi$ of $10-15^{\circ}$ is sufficient. ${ }^{[15]}$ This saddling angle value is obtained from X-ray data and quantum-chemical calculations for the DP forms of all the porphyrins lacking meso-aryl substituents. The synergism of the pyrrole ring tilting and aryl group rotation in meso-aryl-substituted porphyrins allows the formation of highly distorted conformations of DP species as compared to those with other types of peripheral substitution, giving rise to a saddling angle $\varphi$ as high as $28-33^{\circ} .^{[4,7]}$

\section{Photophysical Properties of Mono- and Diprotonated Porphyrins}

The observed changes in the luminescence spectra and photophysical properties upon the formation of mono- and diprotonated forms of porphyrins are due to two factors: a) the formation of the saddle-type conformation of the macrocycle and b) the possibility of complex formation between the positively charged protonated species and anions (first of all acid residues). ${ }^{[4,14,16,23-24]}$

The set of fluorescence spectra of the MP and DP forms of the above-mentioned porphyrins with the most common substitution patterns is shown in Figure 2, and some of their photophysical properties are summarized in Table 1 . The Stokes shift $\Delta \lambda_{\text {Stokes }}=\lambda_{\text {abs }}-\lambda_{\text {ffl }}$ of the fluorescence spectra for the DP species is higher than for the corresponding FB species, with the $\Delta \lambda_{\text {Stokes }}$ value depending strongly on the type of peripheral substitution. ${ }^{[16-18,21,24]}$ For the $\mathrm{H}_{2} \mathrm{P}$ and $\beta$-alkylated porphyrin derivatives $\mathrm{H}_{2}$ TMP, $\mathrm{H}_{2} \mathrm{OMP}$ and $\mathrm{H}_{2} \mathrm{OEP}$ a moderate increase in the $\Delta \lambda_{\text {Stokes }}$ value is observed on going from the FB to protonated species. ${ }^{[24]}$ The values increase from $25-80$ up to $140-200 \mathrm{~cm}^{-1}$. $N$-alkylated derivatives also fit to this dependence. ${ }^{[35]}$ It is interesting to note that for all the molecules except for $\mathrm{H}_{2}$ TMP the Stokes shift values for the MP species exceed those for the DP forms (see Table 1). In the case of meso-aryl substitution the $\Delta \lambda_{\text {Stokes }}$ value increases strongly depending whether the aryl ring has substituents in the ortho-position(s) or not. Thus, for the DP form of $\mathrm{H}_{2}$ TPP the $\Delta \lambda_{\text {Stokes }}$ value increases from 120-140 up to $745-1071 \mathrm{~cm}^{-1}$, whereas for the DP species of
$\mathrm{H}_{2}$ TMesP the $\Delta \lambda_{\text {Stokes }}$ value does not exceed $513 \mathrm{~cm}^{-1}$. $\left.17,18,24\right]$ For the MP forms of meso-aryl-substituted derivatives the Stokes shift values are substantially lower that those of the DP forms and is found to be 251 and $482 \mathrm{~cm}^{-1}$ for $\mathrm{H}_{2}$ TPP and $\mathrm{H}_{2}$ TMesP, respectively. In case of the DP form of $\mathrm{H}_{2} \mathrm{P}$ and $\beta$-alkylated porphyrin derivatives, approximate mirror symmetry of the fluorescence and absorption spectra was observed, ${ }^{[17,18,23,24,28,36,37]}$ and it does not occur for meso-arylsubstituted derivatives. Later on it was found that in solid solution at $77 \mathrm{~K}$ the value of the Stokes shift decreases $\left(\Delta \lambda_{\text {Stokes }}=228 \mathrm{~cm}^{-1}\right.$ has been measured for $\left.\mathrm{H}_{2} \mathrm{TPP}\right)$ and the requirements for the approximate mirror symmetry were almost satisfied. ${ }^{[17]}$ The difference in the Stokes shift value was explained by the different conformational flexibility of these two porphyrin classes, which determines the extent of the macrocycle distortion upon formation of the protonated species. ${ }^{[6]}$ Absence of the mirror symmetry for several $\mathrm{H}_{2}$ TPP derivatives in fluid solution at room temperature should be considered as evidence for conformational rearrangement in the excited singlet $S_{1}$ state. ${ }^{[17]}$

Fluorescence quantum yields $\Phi_{\mathrm{fl}}$ are the subject to changes upon macrocycle protonation, with values found to depend on both macrocycle substitution pattern [17,18,21,23-24,36${ }^{37,]}$ and on the nature of the acid residue when the solution conditions allow the formation of the complexes DP. $2 \mathrm{~A}^{-}$ (where $\mathrm{A}^{-}$denotes the acid residue). ${ }^{[14,23]}$ For the DP form of $\mathrm{H}_{2} \mathrm{OEP}$ the decrease in $\Phi_{\mathrm{fl}}$ was measured as compared to the value found for the FB species $\left(\Phi_{\mathrm{fl}}=0.09^{[52]}\right) \cdot{ }^{[23]}$ Thus, a slight $\Phi_{\mathrm{ff}}$ decrease was found for the cases where the protonation has been done with acids which did not contain heavy atoms (acetic, formic or sulfuric acid): $\Phi_{\mathrm{fl}}=0.07-0.085$. For the acids whose residues have heavy atoms dramatic quenching of the fluorescence has been observed. ${ }^{[23]}$ The fluorescence quantum yield $\Phi_{\mathrm{fl}}$ of the DP form of $\mathrm{H}_{2}$ OEP drops down to $8 \cdot 10^{-5}$ in case of HI. Bases on these observations, the authors hypothesized that fluorescence quenching was due to the internal heavy atom effect in the complexes $\mathrm{H}_{4} \mathrm{OEP}^{2+} \cdot 2 \mathrm{~A}^{-}$which were formed in the organic solvents used in the described experiments. ${ }^{[23]}$ The fluorescence quantum yield $\Phi_{\mathrm{fl}}$ is about the same for both MP and DP forms of $\beta$-alkylated porphyrin derivatives (Table 1). Thus, one can state that attachment of proton(s) to the macrocycle core and the formation of saddle-type conformers barely affect the fluorescence properties of the MP and DP forms for this class of porphyrins. Substantial fluorescence quenching is observed if the complexation with acid residues occurs. In case of $\mathrm{H}\left(\mathrm{N}-\mathrm{CH}_{3}\right) \mathrm{OEP}$, formation of the MP and DP forms leads to substantial fluorescence quenching. ${ }^{[37]}$ Thus, fluorescence quantum yield $\Phi_{\mathrm{fl}}$ for the FB species of $\mathrm{H}(\mathrm{N}$ $\mathrm{CH}_{3}$ )OEP is 0.066 , whereas the $\Phi_{\mathrm{fl}}$ values for the MP and DP species are 0.0082 and 0.0011 , respectively.

The formation of the protonated species is accompanied with an increase in fluorescence probability $k_{\mathrm{f} \cdot}{ }^{[37]}$ Thus, for instance, the FB form of 3,7,13,17-tetramethyl-2,8,12,18tetrabutyl-porphyrin $\left(\mathrm{H}_{2}\right.$ TMTButP) and $\mathrm{H}_{2} \mathrm{P}$ have $k_{\mathrm{fl}}$ values of $4.7 \cdot 10^{7} \mathrm{~s}^{-1}$ and $4.4 \cdot 10^{7} \mathrm{~s}^{-1}$, respectively, whereas they increase more than 3 times for their DP forms. ${ }^{[37]}$ The same trend has been found for the protonated forms of $\mathrm{H}\left(\mathrm{N}-\mathrm{CH}_{3}\right) \mathrm{OEP}$. For the FB molecules, the fluorescence probability $k_{\mathrm{fl}}$ was found to be $4.9 \cdot 10^{7} \mathrm{~s}^{-1}$, while for the DP species it becomes as high as $1.5 \cdot 10^{8} \mathrm{~s}^{-1} \cdot{ }^{[37]}$ 

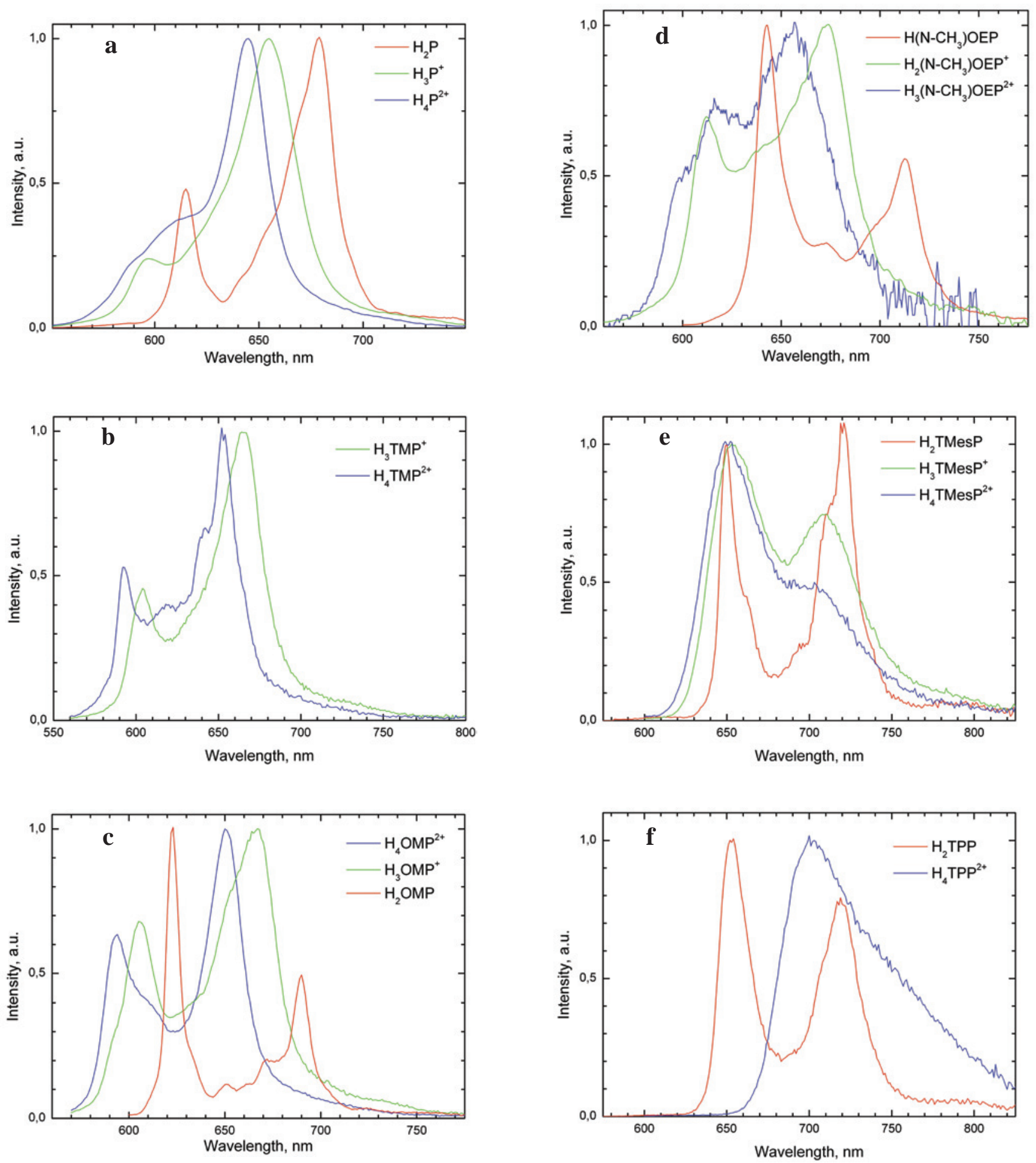

Figure 2. Normalized fluorescence spectra of the FB, MP and DP forms of porphyrins: a) $\mathrm{H}_{2} \mathrm{P}$; b) $\mathrm{H}_{2} \mathrm{TMP}$; c) $\mathrm{H}_{2} \mathrm{OMP}$; d) $\mathrm{H}\left(N-\mathrm{CH} \mathrm{H}_{3}\right) \mathrm{OEP}$; e) $\mathrm{H}_{2} \mathrm{TMesP}$;) $\mathrm{H}_{2} \mathrm{TPP}$.

Table 1. Summary of the photophysical properties of the fluorescent $\mathrm{S}_{1}$ state of FB, MP and DP porphyrin forms at $293 \mathrm{~K}$.

\begin{tabular}{|c|c|c|c|c|c|c|c|c|c|c|c|c|c|c|c|c|}
\hline & & \multicolumn{3}{|c|}{$\mathrm{H}_{2}$ TMP } & \multicolumn{3}{|c|}{$\mathrm{H}_{2} \mathrm{OMP}$} & \multicolumn{3}{|c|}{$\mathrm{H}\left(\mathrm{N}-\mathrm{CH}_{3}\right) \mathrm{OEP}$} & \multicolumn{3}{|c|}{$\mathrm{H}_{2} \mathrm{TPP}$} & \multicolumn{3}{|c|}{$\mathrm{H}_{2}$ TMesP } \\
\hline & & FB & MP & DP* & FB & MP & $\mathrm{DP}$ & FB & MP & DP & FB & $\mathrm{MP}^{\#}$ & $\mathrm{DP}$ & FB & MP & DP \\
\hline \multirow{2}{*}{$\lambda_{\mathrm{fl}}, \mathrm{nm}$} & $Q_{\mathrm{x}}(0,0)$ & - & 604 & $593(583)$ & 623 & 606 & 594 & 643 & 612 & 602sh & 653 & 668 & 701 & 650 & 654 & 650 \\
\hline & $Q_{\mathrm{x}}(1,0)$ & - & 665.5 & $653(642)$ & 690 & 667 & 651 & 713 & 673 & 656 & 720 & 708 & - & 720,5 & 709 & 712sh \\
\hline \multicolumn{2}{|c|}{$\Phi_{\mathrm{ff}} \times 10^{2}$} & - & 7.1 & 6.8 & 15.1 & 8.8 & 9.6 & 6.6 & 0.82 & 0.11 & 9.0 & 7.0 & 9.0 & 8.9 & 18.3 & 24.4 \\
\hline
\end{tabular}

*The values of $\mathrm{S}_{2}$ state are given in parentheses.

${ }^{\#}$ The values are determined for the MP species complexed with tetrakis[3,5-bis-(trifluoromethyl)phenyl]borate. ${ }^{[26]}$ 
For the above described cases of DP. $2 \mathrm{~A}^{-}$complex formation the probability of fluorescence remains high, in spite of the dramatic fluorescence quenching. ${ }^{[14,37]}$ This means that the quenching is not due to a decrease of the probability of emission, but instead due to a sharp increase in the probability of the $S_{1}$ state radiationless deactivation. Since the mechanism of heavy atom effect does not imply perturbation of the radiationless internal $\mathrm{S}_{1} \rightarrow \mathrm{S}_{0}$ conversion probability $k_{\mathrm{IC}}$, it was suggested that $\mathrm{DP} \cdot 2 \mathrm{~A}^{-}$complex formation leads to a substantial increase in the intersystem crossing probability $k_{\mathrm{ISC}}{ }^{[23]}$

Thus, fluorescence quenching observed on going from FB to MP and DP species is due to substantial increase of the probability of radiationless deactivation channels. The value of the Stokes shift $\Delta \lambda_{\text {Stokes }}$ does not increase dramatically and for some of the DP species is close to zero. It means that fluorescence quenching does not result from conformational rearrangement in the excited state, which is expected to populate the conformer with enhanced probability of radiationless deactivation (mainly $k_{\mathrm{IC}}$ ). In the case under consideration, "nonfluorescent" conformer is formed in the electronic ground state. For this conformer the sum of the internal conversion and intersystem crossing probabilities is much higher than that of the fluorescence. Depending on the case, either the intersystem crossing probability $k_{\text {ISC }}$ (upon formation of the DP· $2 \mathrm{~A}^{-}$complexes with heavy atoms) or the internal conversion probability $k_{\text {IC }}$ (for $N$-alkylated derivatives due to formation of a highly distorted macrocycle) dominates.

For meso-aryl-substituted derivatives the value of the fluorescence quantum yield was found to be barely affected by protonation if the heavy atom effect is excluded. ${ }^{[14,21,24]}$ The $\Phi_{\mathrm{fl}}$ value for the DP form of $\mathrm{H}_{2}$ TPP lies in the range 0.08$0.106,{ }^{[17,18,24]}$ whereas $\Phi_{\mathrm{fl}}$ value for the FB species is 0.09 $0.11 .^{[24,52]}$ The shortening of the fluorescence lifetime upon protonation indicates that both radiative and radiationless deactivation rates increase to the same extent. ${ }^{[3]}$ Two-fold build-up of the fluorescence has been observed for the DP form of 5,10,15,20-tetra-2-methylphenylporphyrin as compared to the DP form of $\mathrm{H}_{2}$ TPP. ${ }^{[17,18]}$ For $\mathrm{H}_{2}$ TMesP the increase in the fluorescence quantum yield is higher: the $\Phi_{\mathrm{fl}}$ value is 0.18 for the MP species, and the $\Phi_{\mathrm{fl}}$ value for the DP molecules was found to be as high as 0.24 . These differences in the $\Phi_{\mathrm{fl}}$ upon ortho-substitution of the phenyl rings was explained by changes in the internal $S_{1} \rightarrow S_{0}$ conversion probability $k_{\mathrm{IC}}$, which is supposed to be much smaller with «more orthogonal» positions of the aryl rings. ${ }^{[17,18]}$ The higher value of $k_{\text {IC }}$ in the case of the DP form of $\mathrm{H}_{2}$ TPP has been explained as resulting from intramolecular charge transfer from the meso-phenyl rings to the macrocycle, which is favored upon a «more coplanar» conformation. An alternative interpretation can be suggested on the basis of the difference in the conformation of the DP species, as revealed with X-ray analysis. ${ }^{[6,7,15,24]}$ On one hand, steric hindrance prevents formation of a highly distorted conformation with enhanced internal $\mathrm{S}_{1} \rightarrow \mathrm{S}_{0}$ radiationless deactivation rate $k_{\mathrm{IC}}$. On the other hand, the attachment of protons to the macrocyclic core leads to an increase in the emission probability $k_{\mathrm{fl}}$. The fluorescence quantum yield $\Phi_{\mathrm{fl}}$ value results from the competition of these two probabilities. In the cases discussed above either both of them increase in the same manner upon formation of protonated species (for $\beta$-alkylated porphyrin derivatives) or the radiationless $\mathrm{S}_{1} \rightarrow \mathrm{S}_{0}$ deactivation rate $k_{\mathrm{IC}}$ increases much faster (for $\mathrm{N}$-alkylated derivatives). In orthoaryl-substituted derivatives the macrocycle conformation is rigid due to steric hindrance and there is no possibility to adopt the structure having an enhanced radiationless $\mathrm{S}_{1} \rightarrow \mathrm{S}_{0}$ deactivation rate $k_{\mathrm{IC}}$. As a result, the only contributing factor to the $\Phi_{\mathrm{fl}}$ value is the protonation, which, as was shown above, leads to an increase in the emission probability $k_{\mathrm{fl}}$. As a result, the $\Phi_{\mathrm{fl}}$ value reveals an almost linear growth upon each protonation step $\mathrm{FB} \rightarrow \mathrm{MP} \rightarrow \mathrm{DP}$.

Table 2. Fluorescence quantum yield $\Phi_{\mathrm{fl}}$ upon DP· $2 \mathrm{~A}^{-}$complex formation with halides. ${ }^{[14,23,37]}$

\begin{tabular}{cccccc}
\hline \multirow{2}{*}{$\mathrm{DP}$} & \multicolumn{5}{c}{$\Phi_{\mathrm{fl}} \times 10^{2}$} \\
\cline { 2 - 6 } & no & $\mathrm{F}^{-}$ & $\mathrm{Cl}^{-}$ & \multicolumn{1}{c}{$\mathrm{Br}$} & \multicolumn{1}{c}{$\mathrm{I}^{-}$} \\
\hline $\mathrm{H}_{4} \mathrm{TPP}^{2+}$ & 9.0 & 1.4 & 2.2 & 0.2 & 0.04 \\
$\mathrm{H}_{4} \mathrm{TMTButP}^{2+}$ & 9.0 & - & 2.1 & 0.079 & 0.036 \\
$\mathrm{H}_{4} \mathrm{OEP}^{2+}$ & 8.5 & - & 4.6 & 0.095 & 0.008 \\
\hline
\end{tabular}

The complexation with halides studied for several hydrophobic meso-aryl-substituted derivatives was found to lead also to dramatic fluorescence quenching down to $\Phi_{\mathrm{fl}}=$ $4 \cdot 10^{-4} \cdot{ }^{[14,17]}$ Table 2 summarizes the data on the fluorescence quantum yield $\Phi_{\text {fl }}$ upon DP. $2 \mathrm{~A}^{-}$complex formation with halides for three different porphyrins. It is necessary to note that $\mathrm{DP} \cdot 2 \mathrm{~A}^{-}$complex formation leads also to noticeable changes in the absorption and fluorescence spectra of the DP species. ${ }^{[14,53-57]}$ For example, the maximum of the $0-0$ transition of the uncomplexed DP species of $\mathrm{H}_{2}$ TPP lies at 650-652 nm (depending on the solvent), whereas upon complexation with $\mathrm{PF}_{6}^{-}$or $\mathrm{Cl}^{-}$it shifts to 659 and $665 \mathrm{~nm}$, respectively. The maxima in the fluorescence spectra also show a bathochromic shift. However, the Stokes shift is different in all these cases, indicating that the counter ions influence the conformational dynamics. As a result, different DP conformers are stabilized. For the DP·2A- complexes with halides, ${ }^{[23,26,53,55,57]}$ the bathochromic shift of the spectra increases in the series $\mathrm{Cl}^{-}>\mathrm{Br}>\mathrm{I}^{-}$. The fluorescence quenching in the $\mathrm{DP} \cdot 2 \mathrm{~A}^{-}$complexes with halides was proposed recently to be useful for the design of porphyrin molecular sensors for halides. ${ }^{[54-56,58]}$ The developed method of measurement allows iodide ion concentrations from $1.0 \cdot 10^{-2} \mathrm{M}$ down to $3.0 \cdot 10^{-5} \mathrm{M}$ to be determined. ${ }^{[58]}$ The available sensitivity of such a sensor is almost one order of magnitude higher than others described to date in the literature applying luminescent methods, which provide a sensitivity no more than $1.5 \cdot 10^{-4} \mathrm{M}^{[59]}$

The quantum yield of intersystem $\mathrm{S}_{1} \rightarrow \mathrm{T}_{1}$ crossing changes upon the formation of protonated species with the $\Phi_{\text {ISC }}$ value depending on the structure of the porphyrin. The $\Phi_{\text {ISC }}$ values for the DP forms of mesoporphyrin-IX and protoporphyrin-IX demonstrate a slight increase compared to the FB species up to $\sim 0.9 .{ }^{[60]}$ However, for the DP form of $\mathrm{H}_{2} \mathrm{OEP}$ the $\Phi_{\text {ISC }}$ value decreases down to $0.55 .^{[24]}$ In case of the DP forms of $\mathrm{H}_{2}$ TPP and its para-hydroxyl-substituted derivative $\mathrm{H}_{2}$ THPP, a more pronounced decrease in the $\Phi_{\text {ISC }}$ value has been measured ( 0.30 and 0.29 , respectively). ${ }^{[14,24,61,62]}$ A slightly decreased $\Phi_{\text {ISC }}$ value of 0.51 has been found for the water-soluble para-sulfonyl-substituted derivative $\mathrm{H}_{2}$ TSPP. ${ }^{[21]}$ It is clear that such a behavior of the 
intersystem crossing quantum yield can be explained when multiple factors affect the rates of the intramolecular channels of excitation energy deactivation, with their competition determining the efficiency of the population of the triplet manifold in each particular case.

The analysis of the origin of the observed changes in photophysical properties is simplified in the case of watersoluble porphyrins, since it is known that ions in water solution are hydrated, so the probability that acid residues form the complexes with diprotonated porphyrin being negligible ${ }^{[17,63]}$ Therefore, the changes in the photophysical properties on going from the FB to MP and DP species are due to the electronic effects of proton(s) attachment and the protonation induced conformational rearrangement.

Table 3. Photophysical properties of the FB, MP and DP forms of water-soluble $\mathrm{H}_{2}$ TSPP, $\mathrm{H}_{2}$ TMPyP and $\mathrm{H}_{2}$ TSPC. ${ }^{[16,21,57,64,65]}$

\begin{tabular}{|c|c|c|c|c|c|c|}
\hline Compound & $\begin{array}{r}\Phi_{\mathrm{fl}} \\
\times 10^{2}\end{array}$ & $\begin{array}{c}k_{\mathrm{f}}, \\
10^{7} \mathrm{~s}^{-1}\end{array}$ & $\Phi_{\mathrm{ISC}}$ & $\begin{array}{c}k_{\mathrm{ISC}}, \\
10^{7} \mathrm{~s}^{-1}\end{array}$ & $\Phi_{\mathrm{IC}}$ & $\begin{array}{c}k_{\mathrm{II}}, \\
10^{7} \mathrm{~s}^{-1}\end{array}$ \\
\hline $\mathrm{H}_{2} \mathrm{TSPP}$ & 5.8 & 0.6 & 0.61 & 6.4 & 0.33 & 3.4 \\
\hline $\mathrm{H}_{4} \mathrm{TSPP}^{2+}$ & 13.0 & 3.8 & 0.51 & 14.9 & 0.36 & 10.5 \\
\hline $\mathrm{H}_{2} \mathrm{TSPC}$ & 8.6 & 1.01 & 0.41 & 4.82 & 0.50 & 5.94 \\
\hline $\mathrm{H}_{3} \mathrm{TSPC}^{+}$ & 0.03 & 0.05 & - & - & $\sim 1.0$ & - \\
\hline $\mathrm{H}_{4} \mathrm{TSPC}^{2+}$ & 1.5 & 0.43 & 0.12 & 3.43 & 0.87 & 24.7 \\
\hline $\mathrm{H}_{2} \mathrm{TMPyP}$ & 4.4 & 0.85 & 0.85 & 16.5 & $\sim 0.1$ & 0.2 \\
\hline $\mathrm{H}_{4} \mathrm{TMPyP}^{2+}$ & 2.0 & 2.3 & - & - & - & - \\
\hline
\end{tabular}

However, when a large excess of the acid is added (in the order of $1 \mathrm{M}$ ), complexation of the DP species $\mathrm{w}$ ith acid residues is observed. ${ }^{[17,57]}$ Stern-Volmer plots were plotted for the fluorescence quenching with increased amounts of haloacids, and different slopes have been observed when different acids had been used for the titrations. ${ }^{[17]}$ As a result, the fluorescence quantum yield $\Phi_{\mathrm{fl}}$ measured for the DP form of 5,10,15,20-tetrakis( $N, N, N$-trimethyl-4-aminophenyl)porphyrin $\left(\mathrm{H}_{2}\right.$ TAPP) ranges from 0.125 (with addition of $1 \mathrm{M}$ $\mathrm{H}_{2} \mathrm{SO}_{4}$ ) to less than $5 \cdot 10^{-4}$ (with addition of $\left.1 \mathrm{M} \mathrm{HI}\right){ }^{[57]}$

In Table 3 the photophysical parameters of the FB, MP and DP forms of two water-soluble porphyrins and one hydroporphyrin (chlorin) are shown. In the case of the porphyrins the formation of the DP species leads to an increase in the fluorescence probability $k_{\mathrm{fl}}$. However, due to competition with enhanced radiationless deactivation rates, the fluorescence quantum yield $\Phi_{\mathrm{fl}}$ increases for the DP form of $\mathrm{H}_{2}$ TSPP and decreases for the DP species of $\mathrm{H}_{2}$ TMPyP. In the latter case, the sum of $k_{\mathrm{ISC}}$ and $k_{\mathrm{IC}}$ is $11,4 \cdot 10^{8} \mathrm{~s}^{-1}$, i.e. almost six times higher as compared to that for the FB, whereas $k_{\mathrm{fl}}$ increases about three times. The reverse relationship holds in case of the DP form of $\mathrm{H}_{2}$ TSPP and results in an enhancement of the fluorescence quantum yield up to 0.13 . One can point out the substantial quantum yield of the internal conversion in case of the FB and DP forms of $\mathrm{H}_{2}$ TSPP. The $\Phi_{\text {IC }}$ value remains about the same upon the DP species formation, so the increase in the fluorescence quantum yield is mainly at the expense of the intersystem crossing quantum yield. The global analysis procedure has been applied to achieve the absorption and fluorescence spectra of the MP form of $\mathrm{H}_{2}$ TSPP. ${ }^{[21]}$ The fluorescence quantum yield for the MP form of $\mathrm{H}_{2}$ TSPP was expected to be substantially lower than that for the
FB. Taking into account the substantial shortening of the fluorescence lifetime $\tau_{\mathrm{S}}$ of the MP form down to 1.3 ns, as compared to those for the FB (9.6 ns) and the DP (3.4 ns) species, strong enhancement of the radiationless deactivation channels was suggested. ${ }^{[21]}$ The fluorescence quantum yield has been estimated as low as $3 \cdot 10^{-4}$ for the MP species of $\mathrm{H}_{2}$ TSPC. ${ }^{[16]}$ The comparison of these $\Phi_{\mathrm{ff}}$ values with that reported for the MP form of $\mathrm{H}_{2}$ TPP complexed with tetrakis[3,5-bis(trifluoromethyl)-phenyl]borate (see Table 1$)^{[26]}$ indicates that binding of the counter ion favors the fluorescence deactivation of the lowest singlet state.

The fluorescence quenching observed for the DP form of $\mathrm{H}_{2}$ TMPyP and $\mathrm{H}_{2}$ TSPC seems to have a different origin. In the former case the emission probability can not compete with the probability of intersystem crossing, and as a result the triplet manifold is mainly populated. For the latter the internal conversion dominates in the deactivation. The energy gap between the $\mathrm{S}_{1}$ and ground state $\mathrm{S}_{0}$ for the DP form of $\mathrm{H}_{2}$ TSPC is about the same as it was for the porphyrin counterparts. Therefore, a simple energy gap law cannot explain the substantially larger value of $k_{\mathrm{IC}}$. Changes in the level of saturation of the $\pi$-conjugated system of the chlorin macrocycle due to the pyrrole reduction was proposed to be the reason for the enormous increase in the molecular flexibility, leading to an increase in the internal conversion rate. ${ }^{[16]}$ Enhanced flexibility of the reduced macrocycle as compared with that of the porphyrin facilitates the motion along the potential energy surface leading to the conformational substates with increased probability of nonradiative deactivation of the excited states. ${ }^{[66]}$ The importance of these factors is discussed extensively for tetrapyrrolic compounds with high degrees of nonplanar distortions. ${ }^{[6,10]}$

The results of the analysis of the photophysical properties indicate that the radiationless internal $S_{1} \rightarrow S_{0}$ conversion plays an important role in the excitation energy deactivation of protonated forms of porphyrins. Up to $90 \%$ of the excited species in some cases deactivate through this channel. ${ }^{[16,24]}$ Enhancement of the radiationless deactivation in the singlet manifold is proposed to be due to conformational rearrangement in the excited $\mathrm{S}_{1}$ state, whose signature is the large Stokes shift of the fluorescence spectra. ${ }^{[17]} \mathrm{A}$ model has been proposed, ${ }^{[24]}$ according to which points of a "deactivation funnel” are located on the potential surface of the singlet $S_{1}$ state. These points are separated from the FrankCondon equilibrium conformation with moderate (estimated as $\left.1300-1400 \mathrm{~cm}^{-1}\right)^{[24]}$ activation barriers. In the deactivation funnel points the energy gap $\Delta E\left(\mathrm{~S}_{1}-\mathrm{S}_{0}\right)$ between the potential surfaces of the first excited singlet $\mathrm{S}_{1}$ and ground state singlet $\mathrm{S}_{0}$ states is substantially lower as compared to that in the equilibrium conformation, from which the fluorescence is emitted. A decrease in the $\Delta E\left(\mathrm{~S}_{1}-\mathrm{S}_{0}\right)$ value is known to be a factor leading to the enhancement of the radiationless deactivation probability in the singlet manifold. ${ }^{[67,68]}$ Thus, the molecules in the excited $\mathrm{S}_{1}$ state can either deactivate through the emission of a fluorescence quantum or deactivate by a radiationless channel if the energy barrier to achieve the deactivation funnel point has been overcome. However, one should stress that the contribution of this mechanism in the total deactivation of the lowest singlet state of protonated porphyrin species can vary within wide limits, as has been demonstrated above. 


\section{Mechanisms of Fluorescence Quenching in Complexes of Diprotonated Porphyrins with Halides}

Different mechanisms of fluorescence quenching in the DP.2A- complexes of diprotonated porphyrins with halides have been proposed to date. ${ }^{[10,14,17,23,25]}$ The first explanation of the dramatic decrease in the fluorescence quantum yield $\Phi_{\mathrm{fl}}$ value involved the enhancement of the intersystem crossing probability due to an internal heavy atom effect. ${ }^{[14,17,23,25]}$ Halides are known to have large spinorbit coupling constants $\zeta$, which sharply increase with increase in the atomic number of the halide ion (see Table 4). The set of experimental photophysical data on the DP species formed with $\mathrm{HCl}, \mathrm{HBr}$ and $\mathrm{HI}$ acids $^{[23]}$ has been qualitatively explained based on the internal heavy atom effect. Much later, ${ }^{[10,25]}$ the possibility of the other quenching mechanism, involving charge transfer from the halides to the diprotonated porphyrin macrocycle, has been discussed on the basis of quantum-chemical calculations. It was proposed that in the DP.2 $\mathrm{A}^{-}$complexes low-lying charge transfer states are formed. To date, however, there are no reliable evidences of intramolecular charge transfer in the DP. $2 \mathrm{~A}^{-}$complexes. Moreover, the quenching by means of internal heavy atom effects seems to be proven experimentally, since efficient quenching has been observed in low polar solvents (toluene, dichloromethane), where sufficient stabilization of the charge-transfer state was not expected.

The photophysical properties of the DP form of $\mathrm{H}_{2}$ TMTButP are summarized in Table 4. One can see that upon going from uncomplexed DP species to the $\mathrm{DP} \cdot 2 \mathrm{~A}^{-}$complexes with halides a moderate decrease in the fluorescence probability is observed. At the same time a substantial enhancement of the intersystem crossing probability $k_{\text {ISC }}$ occurs. Radiationless internal $\mathrm{S}_{1} \rightarrow \mathrm{S}_{0}$ conversion is not affected. The result of the complexation is the decrease in fluorescence quantum yield $\Phi_{\mathrm{f}}$, which becomes larger with increase in the atomic number of the complexed halide.

Table 4. Photophysical properties of the DP form of $\mathrm{H}_{2}$ TMTButP and its DP·2A- complexes with halides. ${ }^{[37]}$

\begin{tabular}{ccccccc}
\hline Compound & $\begin{array}{c}\Phi_{\mathrm{fl}} \\
\times 10^{2}\end{array}$ & $\begin{array}{c}k_{\mathrm{f}}, \\
10^{7} \mathrm{~s}^{-1}\end{array}$ & $\Phi_{\mathrm{ISC}}$ & $\begin{array}{c}k_{\mathrm{ISC}}, \\
10^{8} \mathrm{~s}^{-1}\end{array}$ & $\begin{array}{c}\Phi_{\mathrm{IC}} \\
\times 10^{-2}\end{array}$ & $\begin{array}{c}\zeta, \\
\mathrm{cm}^{-1}\end{array}$ \\
\hline $\mathrm{DP}$ & 9.0 & 1.86 & 0.88 & 1.51 & $<1.0$ & - \\
$\mathrm{DP} \cdot 2 \mathrm{Cl}^{-}$ & 2.1 & 1.40 & 0.98 & 6.53 & $<1.0$ & 587 \\
$\mathrm{DP} \cdot 2 \mathrm{Br}$ & 0.079 & $\geq 0.79$ & 1.0 & 100 & $<0.1$ & 2460 \\
$\mathrm{DP} \cdot 2 \mathrm{I}^{-}$ & 0.036 & - & 1.0 & $\geq 100$ & $<0.1$ & 5060 \\
\hline
\end{tabular}

The hypothesis on the internal heavy atom effect can be proven with a double logarithmic plot where the analyzed parameter is plotted versus the spin-orbit coupling constant $\zeta$ squared. ${ }^{[69]}$ The relationship between the measured fluorescence quantum yield $\Phi_{\mathrm{fl}}$ and $\Sigma \zeta^{2}$ is presented in Figure 3a. All the available literature data on the fluorescence quantum yields $\Phi_{\mathrm{fl}}$ of the DP.2A- complexes with halides are included in this plot. $[14,17,18,23,37]$ It is evident that a satisfactory approximation of the dependencies can be achieved with a linear function. Analysis of the plot indicates that practically the same slope of the linear function holds for all the dependencies, in spite of both the different molecular structures of the complexed DP species and the different temperatures at which the measurements have been undertaken.

The relationship between the value of the intersystem $\mathrm{S}_{1} \rightarrow \mathrm{T}_{1}$ crossing probability $k_{\mathrm{ISC}}$ and $\Sigma \zeta^{2}$ is presented in Figure $3 \mathrm{~b}$. One can see that the $k_{\text {ISC }}$ value increases practically linearly with increase in $\Sigma \zeta^{2}$. Both revealed relationships taken together form the unambiguous evidence for the dominating role of the heavy atom effect in the fluorescence quenching in the DP.2A- complexes with halides. Growth of the population of the triplet manifold due to an increase in the intersystem crossing probability $k_{\text {ISC }}$ takes place at the expense of the fluorescence quenching. Strong enhancement
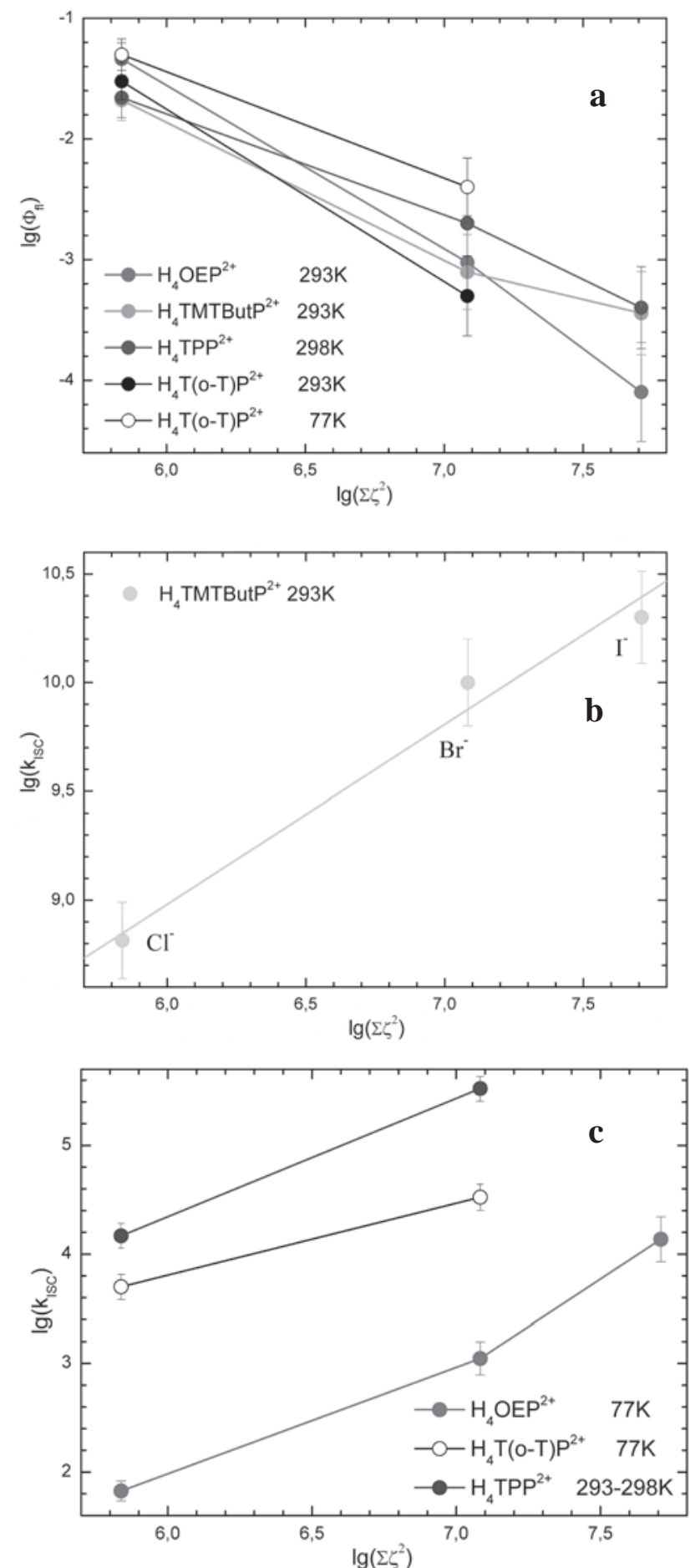

Figure 3. Double logarithmic plots for: a) $\Phi_{\mathrm{f}}$, b) $k_{\mathrm{ISC}}\left(\mathrm{S}_{1} \rightarrow \mathrm{T}_{1}\right)$ and c) $k_{\mathrm{ISC}}\left(\mathrm{T}_{1} \rightarrow \mathrm{S}_{0}\right)$ as a function of the sum of spin-orbit coupling constant squared $\Sigma \zeta^{2}$ in the DP.2A- complexes with halides. 
of the intersystem crossing probability $k_{\mathrm{ISC}}$ with increase of the atomic number of the complexed halide leads to conditions when neither the fluorescence probability $k_{\mathrm{ff}}$ nor the internal $\mathrm{S}_{1} \rightarrow \mathrm{S}_{0}$ conversion probability $k_{\mathrm{IC}}$ can compete with it. As a result, the intersystem $\mathrm{S}_{1} \rightarrow \mathrm{T}_{1}$ crossing becomes the main channel of the lowest singlet $S_{1}$ state deactivation of the DP.2A- complexes with halides, and in particular cases of bromine $\mathrm{Br}$ and iodine I- the value of the quantum yield of the intersystem crossing $\Phi_{\text {ISC }}$ (within experimental error) equals to $1.0 .^{[37]}$ This observation is in disagreement on a matter of principle with the concept proposed earlier. ${ }^{[17,18,24,70]}$

According to that the DP species have unconditionally high efficiency of the internal $\mathrm{S}_{1} \rightarrow \mathrm{S}_{0}$ conversion. In the case described above, the quantum yield of the internal conversion $\Phi_{\text {ISC }}$ is 0 (within experimental error). Thus, these recent data indicate that this earlier concept should be considered to be valid in the particular cases only when specific requirements are satisfied. In the general case, it is not possible to claim that all the DP species must have unconditionally high efficiency of internal $\mathrm{S}_{1} \rightarrow \mathrm{S}_{0}$ conversion.

Turning back to the experimental evidences of the heavy atom effect on the excited states deactivation in the $\mathrm{DP} \cdot 2 \mathrm{~A}^{-}$complexes with halides, a question on the relationship between the intersystem $\mathrm{T}_{1} \rightarrow \mathrm{S}_{0}$ crossing and the $\Sigma \zeta^{2}$ needs to be examined. Indeed, heavy atoms are known to effect both the $\mathrm{S}_{1} \rightarrow \mathrm{T}_{1}$ and $\mathrm{T}_{1} \rightarrow \mathrm{S}_{0}$ intersystem crossing rates. ${ }^{[69,71]}$ The intersystem $\mathrm{T}_{1} \rightarrow \mathrm{S}_{0}$ crossing rate can be taken as the reciprocal of the triplet state lifetime $\tau_{T}^{-1}$. The first set of measurements of the triplet state lifetime in the $\mathrm{H}_{2} \mathrm{OEP} \cdot 2 \mathrm{~A}^{-}$complexes with halides at $77 \mathrm{~K}$ has been reported in the middle of the seventies. ${ }^{[23]}$ The authors stated that the triplet state lifetime $\tau_{\mathrm{T}}$ depends on the type of acid residue and in case of complexes with halides much shorter $\tau_{\mathrm{T}}$ values have been measured. The logarithmic dependence of the DP triplet state deactivation rate $k_{\text {ISC }}$ on the sum of the spin-orbit coupling constants $\lg \left(\Sigma \zeta^{2}\right)$ in complexes with $\mathrm{Cl}^{-}, \mathrm{Br}^{-}$and $\mathrm{I}^{-}$has a linear character (in good approximation) (Figure 3c). Once again this fact proves the major role of the internal heavy effect in the formation of excitation energy deactivation channels in the DP.2Acomplexes. The same behavior holds for the DP form of orthomethylsubstituted derivatives of $\mathrm{H}_{2}$ TPP at $77 \mathrm{~K}^{[14,17]}$ as well as for $\mathrm{H}_{2}$ TPP at $295 \mathrm{~K}^{[25]}$ These data are plotted also in Figure $3 \mathrm{c}$. Concerning the triplet state lifetime $\tau_{\mathrm{T}}$ of the DP form of watersoluble derivatives, which do not form complexes with acid residues in water solution, it is expected to remain practically the same as it was for the FB species. ${ }^{[21]}$

Thus, heavy atom effects play a dominating role in the excitation energy deactivation of the DP. $2 \mathrm{~A}^{-}$complexes with halides. On the contrary, the high efficiency of the internal $\mathrm{S}_{1} \rightarrow \mathrm{S}_{0}$ conversion is not an integral feature of the DP species, and for particular molecules it is observed neither for uncomplexed DP species nor for the DP.2A- complexes. The probabilities of intramolecular channels of excitation energy deactivation in the DP forms of porphyrins can substantially vary as a function of the molecular structure of the porphyrin and microenvironmental conditions.

\section{Conclusions}

The formation of mono- and diprotonated forms of porphyrins leads to the substantial changes in their spectral and photophysical properties. The observed changes result from multiple factors. Attachment of proton(s) and formation of the nonplanar macrocycle conformers leads to molecular symmetry changes as well as induces the electronic effects. Positively charged protonated forms were shown to interact readily with anions and the influence of this interaction bring substantial perturbation for spectral and photophysical features of protonated forms. Excitation energy deactivation channels in mono- and diprotonated forms are formed in the result of competition between the fluorescent $S_{1} \rightarrow S_{0}$ deactivation, intersystem $\mathrm{S}_{1} \rightarrow \mathrm{T}_{1}$ crossing and radiationless internal $S_{1} \rightarrow S_{0}$ conversion rates. The sensitivity of porphyrin to all these factors depends strongly on the molecular structure and mediated with microenvironment conditions. However, there is no yet the detailed understanding of the mechanisms of all the phenomena involved. To date, phenomenological description is possible only and additional experimental efforts elaborating new molecular structures are required.

The protonated forms of porphyrins offer the opportunities for organic nanotechnologies in the development of molecular scale systems for detection of specific analytes. ${ }^{\text {[72] }}$ They are able to provide a combination of capture and report functions, fast response and can be accumulated in ultrasmall areas or volumes. These studies are in initial stage, but first results seem to be encouraging.

Acknowledgements. This work was supported by the Foundation for Fundamental Research of the Republic of Belarus (project Ch10R-001) and a FP-7 grant from the EC for Research, Technological Development and Demonstration Activities, "Dendrimers for Photonic Devices" IRSESPEOPLE-2009-247260-DphotoD, under the "International Research Staff Exchange Scheme”. W. Maes also thanks the FWO (Fund for Scientific Research - Flanders), the KU Leuven, Hasselt University and the Ministerie voor Wetenschapsbeleid for continuing financial support.

\section{References}

1. Andrianov V.G., Malkova O.V. Macroheterocycles 2009, 2, 130-138.

2. Phillips J.N. Physico-Chemical Properties of Porphyrins. In: Comprehensive Biochemistry, Vol. 9 (Florkin M., Stotz E., Eds.). Amsterdam: Elsevier, 1963. p. 34-73.

3. Gurinovich G.P, Sevchenko A.N., Solovyov K.N. Spectroscopy of Chlorophyll and Related Compounds, Minsk: Nauka i Tekhnologiya, 1968. 520 p. [Engl. transl.: Nat. Tech. Informat. Serv. US Dept. of Commerce, Springfield, Virginia, 1971, 506 p.]

4. Stone A., Fleischer E.B. J. Am. Chem. Soc. 1968, 90, 27352748.

5. Andrianov V.G., Malkova O.V., Berezin D.B. In: Uspekhi Khimii Porfirinov, Vol. 3 [Advances in Porphyrin Chemistry] (Golubchikov O.A., Ed.). St. Petersburg: St. Petersburg State University, 2001. pp. 107-129. (in Russ.)

6. Senge M.O. J. Photochem. Photobiol. B: Biol. 1992, 16, 3-36.

7. Cheng B., Munro O.Q., Marques H.M., Scheidt W.R. J. Am. Chem. Soc. 1997, 119, 10732-10742.

8. Milgrom L.R. The Colours of Life: An Introducrtion to the Chemistry of Porphyrins and Related Compounds. Oxford: Oxford University Press, 1997. 249 p.

9. Shelnutt J.A., Song X.-Z., Ma J.-G., Jia S.-L., Jentzen W., Medforth C.J. Chem. Soc. Rev. 1998, 27, 31- 41. 
10. Gael V.I., Kuzmitsky V.A., Solovyov K.N. J. Appl. Spectrosc. 1999, 66, 559-562.

11. Gael V.I., Kuzmitsky V.A., Solovyov K.N. J. Appl. Spectrosc. 2000, 67, 696-702.

12. Ma S.Y. Chem. Phys. Lett. 2000, 332, 603-610.

13. Chen D.-M., Liu X., He T.-J., Liu F.-C. Chem. Phys. 2003, 289, 397-407.

14. Rosa A., Ricciardi G., Baerends E.J., Romeo A., Scolaro L.M. J. Phys. Chem. A 2003, 107, 11468-11482.

15. Rosa A., Riccardi G., Baerends E.J. J. Phys. Chem. A 2006, 110, 5180-5190.

16. Kruk M.M., Braslavsky S.E. J. Phys. Chem. A 2006, 110, 3414-3425.

17. Knyukshto V.N., Solovyov K.N.,Egorova G.D.Biospectroscopy 1998, 4, 121-133.

18. Knyukshto V.N., Solovyov K.N., Mironov A.F., Egorova G.D., Efimov A.V. Opt. Spectrosc. 1998, 85, 592-600.

19. Fleischner E.B., Webb L.E. J. Phys. Chem. 1963, 67, 11311133.

20. Hambright P., Fleischer E.B. Inorg. Chem. 1970, 9, 1757-1761.

21. Gensch T., Viappiani C., Braslavsky S. J. Am. Chem. Soc. 1999, 121, 10573-10582.

22. Ivanova Yu.B., Semeikin A.S., Mamardashvili N.Zh. Rus. J. General Chem. 2009, 79, 1029-1034.

23. Gradushko A.T., Knuykshto V.N., Solovyov K.N., Tsvirko M.P. J. Appl. Spectrosc. 1975, 23, 444-452.

24. Chirvony V.S., van Hoek A., Galievsky V.A., Sazanovich I.V., Schaafsma T.J., Holten D. J. Phys. Chem. B 2000, 104, 99099917.

25. Avilov I.V., Panarin A.Yu., Chirvony V.S. Chem. Phys. Lett. 2004, 389, 352-358.

26. De Luca G., Romeo A., Scolaro L.M., Ricciardi G., Rosa A. Inorg. Chem. 2007, 46, 5979-5988.

27. Ogoshi H., Watanabe E., Yoshida Z. Tetrahedron 1973, 29, 3241-3245.

28. Tsvirko M.P., Solovyov K.N., Knuykshto V.N., Gradushko A.T. J. Appl. Spectrosc. 1975, 23, 643-647.

29. Sinclair R.S., Tait D, Truscott T.G. J. Chem. Soc., Faraday Trans. I 1980, 768, 417- 424.

30. Aronoff S., Calvin M. J. Org. Chem. 1943, 8, 205-209.

31. Almarsson O., Blasko A., Bruice T.C. Tetrahedron 1993, 49, 10239-10252.

32. Liao Y., Ma S. Internet Electron. J. Mol. Des. 2006, 5, 530-541.

33. Mason S.F. J. Chem. Soc. 1958, 976-983.

34. Closs G.L., Katz J.J., Pennigton F.C., Thomas M.R., Strain H.H. J. Am. Chem. Soc. 1963, 85, 3809-3821.

35. Jackson A.H., Dearden G.R. Annals New York Acad. Sci. 1973, 206, 151-175.

36. Kruk M.M., Starukhin A.S. In: Proceedings of IX Int. Conf. "Molecular, Membrane and Cellular Mechanisms of Functioning of biosystems”. Minsk, 2010, p. 83-85. (in Russ.)

37. Kruk M.M., Starukhin A.S. In: Proceedings of VIII Int. Conf. "Laser Physics and Optical Technologies". Minsk, 2010, p. 216-219. (in Russ.)

38. Gouterman M., Wagniere G., Snyder L.R. J. Mol. Struct. 1963, $11,108-127$.

39. Gouterman M. Optical Spectra and Electronic Structure of Porphyrins and Related Rings. In: The Porphyrins, Vol. 3 (Dolphin D., Eds.). New York, 1978. p. 1-165.

40. Verma A.L., Bernstein H.J. J. Chem. Phys. 1974, 61, 2560-2565.

41. Starukhin A.S., Kruk M.M., Czerwieniec R. J. Lumin. 2008, 128, 531-536.

42. Shul'ga A.M., Gladkov L.L., Stanishevsky I.V., Starukhin A.S. Theor. Exp. Chem. 1985, 21, 431-439.
43. Knyukshto V.N., Shul'ga A.M., Sagun E.I., Zenkevich E.I. Opt. Spectrosc. 2006, 101, 952-958.

44. Starukhin A.S., Kruk M.M. Opt. Spectrosc. 2007, 103, 298303.

45. Kruk M.M., Starukhin A.S., Czerwieniec R. J. Porphyrins Phthalocyanines 2008, 12, 1201-1210.

46. Starukhin A.S., Kruk M.M. J. Porphyrins Phthalocyanines 2009, 13, 957-963.

47. Brodhurst M.J., Grigg R., Shelton G., Johnson A.W. Chem. Commun. 1970, 231-233.

48. Grigg R., Sweeney A., Dearden G.R., Jackson A.H. Chem. Commun. 1970, 1273-1274.

49. Al-Hazimi H.M.G., Jackson A.H., Johnson A.W., Winter M. J. Chem. Soc., Perkin Trans. I 1977, 98-103.

50. Lavallee D.K., Gebala A.E. Inorg. Chem. 1974, 13, 20042008.

51. Gael V.I., Kuzmitsky V.A., Solovyov K.N. J. Appl. Spectrosc. 1996, 63, 932-942.

52. Knyukshto V.N., Zenkevich E.I., Sagun E.I., Shul'ga A.M., Bachilo S.M. Chem. Phys. Lett. 1998, 297, 97-108.

53. Ivanova Yu.B., Sheinin V.B., Mamardashvili N.Zh. Rus. J. Gen. Chem. 2007, 77, 1561-1568.

54. Kruk M.M., Starukhin A.S., Mamardashvili N.Zh., Sheinin V.B., Ivanova Yu.B. J. Appl. Spectrosc. 2007, 74, 750-755.

55. Kruk M.M., Ivanova Yu.B., Sheinin V.B., Starukhin A.S., Mamardashvili N.Zh., Koifman O.I. Macroheterocycles 2008, 1, 50-58.

56. Kruk M.M., Starukhin A.S., Mamardashvili N.Zh., Mamardashvili G.M., Ivanova Yu.B., Maltseva O.V. J. Porphyrins Phthalocyanines 2009, 13, 1148-1158.

57. Harriman A., Richoux M.-C. J. Photochem. 1984, 27, 205214.

58. Kruk M.M., Starukhin A.S., Mamardashvili N.Zh., Sheinin V.B., Ivanova Yu.B. Russian Federation patent No. 2345352 (27.01.2009).

59. Eggins B. Chemical Sensors and Biosensors. Chichester: John Wiley \& Sons, 2002. 335 p.

60. Chirvony V.S. Izv. Akad. Nauk USSR, Ser. Fiz. 1975, 39, 24002403 (in Russ.).

61. Chirvony V.S., Sagun E.I., Dzhagarov B.M. J. Appl. Spectosc. 1977, 27, 167-170.

62. Bonnett R., McGarvey D.J., Harriman A., Land E.J., Truscott T.G., Winfield U.-J. Photochem. Photobiol. 1988, 48, 271-276.

63. Reichardt C. Solvents and Solvent Effects in Organic Chemistry, 2nd ed. Weinheim: VCH Publishers, 1988. 736 p.

64. Chirvony V.S., Galievsky V.A., Kruk N.N., Dzhagarov B.M., Turpin P.-Y. J. Photochem. Photobiol., B 1997, 40, 154-162.

65. Kruk N.N., Dzhagarov B.M., Galievsky V.A., Chirvony V.S., Turpin P.-Y. J. Photochem. Photobiol., B 1998, 42, 181-190.

66. Stolzenberg A.M., Stershic A.T. J. Am. Chem. Soc. 1988, 110, 6391-6402.

67. Siebrand W. J. Chem. Phys. 1967, 46, 440-447.

68. Losev A.P., Sagun E.I., Nichiporovich I.N. Rus. Chem. Phys. 1987, 6, 907-914.

69. McGlynn S.P., Azumi T., Kinoshita M. Molecular Spectroscopy of the Triplet State. Prentice-Hall, Inc., Englewood Cliffs, New Jersey, 1969. 448 p.

70. Sazanovich I.V., Galievsky V.A., van Hoek A., Schaafsma T.J., Malinovskii V.L., Holten D., Chirvony V.S. J. Phys. Chem. B. 2001, 105, 7818-7829.

71. Solovyov K.N., Borisevich E.A. Usp. Fiz. Nauk 2005, 175, 247-270 (in Russ.).

72. Xie Y., Hill J.P., Charvet R., Ariga K. J. Nanoscie. Nanotechnol. 2007, 7, 2969-2993. 